\title{
ACHADOS HEMATOLÓGICOS EM CÃES COM CINOMOSE EM BOM JESUS/PI
}

\author{
Richard Átila de Sousa ${ }^{1}$, Jonismar Castro Baião ${ }^{2}$, Jamile Prado dos Santos ${ }^{3}$, \\ Leandro Branco Rocha ${ }^{3}$, Luciana Pereira Machado ${ }^{4}$ \\ ${ }^{1}$ Pós-Graduando do Programa de Mestrado em Ciência Animal da Universidade \\ Federal do Piauí, Campus Ministro Petrônio Portella, Teresina, Brasil \\ (richard@ufpi.edu.br) \\ ${ }^{2}$ Discente do Curso de Medicina Veterinária da Universidade Federal do Piaú́, \\ Campus Prof. ${ }^{\text {a }}$ Cinobelina Elvas, Bom Jesus, Brasil \\ ${ }^{3}$ Prof.(a) Doutor(a) do Curso de Medicina Veterinária da Universidade Federal de \\ Sergipe, Campus São Cristovão, Aracaju, Brasil \\ ${ }^{4}$ Profa Doutora do Curso de Medicina Veterinária da Universidade Federal do Piauí, \\ Campus Prof. ${ }^{\text {a }}$ Cinobelina Elvas, Bom Jesus, Brasil
}

Recebido em: 08/09/2015 - Aprovado em: 14/11/2015 - Publicado em: 01/12/2015 DOI: http://dx.doi.org/10.18677/Enciclopedia_Biosfera_2015_065

\begin{abstract}
RESUMO
A cinomose é uma doença infecciosa viral causada por um RNA vírus pertencente a família Paramyxoviridae do gênero Morbillivirus que acomete cães domésticos e outros carnívoros. O conhecimento dos parâmetros laboratoriais da doença pode orientar no diagnóstico e prognóstico. Este trabalho teve como objetivo caracterizar as alterações hematológicas de cães com quadro clínico de cinomose atendidos na Universidade Federal do Piauí, no município de Bom Jesus. Participaram desse estudo 18 cães com diagnóstico clínico de cinomose, sendo sete machos e 11 fêmeas, com idade variando de três meses a cinco anos. Foram coletados de 3 a 5 $\mathrm{mL}$ de sangue venoso por venopunção jugular para as avaliações hematológicas. As alterações observadas com maior frequência foram anemia $(72,2 \%)$, linfócitos reativos $(72,2 \%)$, monocitose $(55,5 \%)$, linfopenia $(38,8 \%)$, trombocitopenia $(38,8 \%)$, leucocitose $(33,3 \%)$, neutrofilia $(33,3 \%)$, neutrófilos hipersegmentados $(33,3 \%)$ e monócitos ativados (27,7\%). Em $22,2 \%$ dos animais, foram observadas inclusões de Lentz em leucócitos e eritrócitos, confirmando o diagnóstico clínico da cinomose. Conclui-se que a anemia e a ativação dos linfócitos são os achados mais relevantes na cinomose canina, podendo estar ou não associados à linfopenia. A avaliação da morfologia leucocitária e pesquisa dos corpúsculos de Lentz deve ser realizada em todos os animais com suspeita de cinomose canina.
\end{abstract}

PALAVRAS-CHAVE: caninos, corpúsculo de Lentz, leucócitos.

\section{HEMATOLOGIC FINDINGS IN CINOMOSE CANINE IN BOM JESUS/PI}

\begin{abstract}
The canine cinomose is a viral infectious disease caused by RNA virus belonging to Paramyxoviridae family and Morbillivirus genus that attack domestic dogs and others carnivores. Knowledge of laboratory parameters of disease can guide the diagnosis and prognosis. This study aimed to characterize the hematological alterations of dogs with clinical cinomose treated at the Federal University of Piaui in Bom Jesus. ENCICLOPÉDIA BIOSFERA, Centro Científico Conhecer - Goiânia, v.11 n.22; p. 1 2015
\end{abstract}


Participants were 18 dogs with clinical diagnosis of cinomose, seven males and 11 females, with age ranging of three months to five years. Were coleted 3 to $5 \mathrm{~mL}$ of venous blood by jugular venipuncture for hematological evaluation. The changes most frequently observed were anemia $(72.2 \%)$, reactive lymphocytes $(72.2 \%)$, monocytosis (55.5\%), lymphopenia (38.8\%), thrombocytopenia (38.8\%), leukocytosis $(33,3 \%)$, neutrophils (33.3\%), hypersegmented neutrophils (33.3\%) and activated monocytes $(27.7 \%)$. In $22.2 \%$ of the animals, Lentz inclusions were observed in leukocytes and erythrocytes, confirming a clinical diagnosis of cinomose. It follows that anemia and lymphocyte activation are the most important findings in canine cinomose, and may be or not related to lymphopenia. The evaluation of leukocyte morphology and research of corpuscles Lentz should be performed in all animals suspected of canine cinomose.

KEYWORDS: canine, corpuscle Lentz, hemogram

\section{INTRODUÇÃO}

A cinomose é uma doença viral infecciosa que acomete principalmente os cães e em outros animais, causada pelo vírus da cinomose canina (VCC), do gênero Morbillivirus da família Paramyxoviridae (KING et al., 2011; HEADLEY et al., 2012). Acomete cães domésticos (Canis familiares) e carnívoros como raposas, furões, leões, leopardos, guepardos e tigres (OLIVEIRA et al., 2009). Pode acometer animais de qualquer idade, raça e sexo, com uma maior predileção por filhotes e cães não vacinados, e sendo considerada a segunda doença com maior taxa de letalidade (NELSON \& COUTO, 2010; GREENE \& APPEL, 2011).

Animais infectados transmitem o vírus para outros animais através de aerossóis e gotículas infectantes de excreções e secreções corpóreas (HEADLEY et al., 2012). O VCC é um vírus envelopado, com genoma RNA fita simples e polaridade negativa. A infecção provoca doença multisistêmica de evolução aguda, subaguda ou crônica, muito contagiosa e que além dos sinais clínicos sistêmicos pode também evoluir para graves sinais neurológicos (OLIVEIRA et al., 2009). Os principais sinais clínicos são as secreções oculares e nasais, hiperqueratose dos coxins digitais, dermatite postular, enterite catarral ou hemorrágica, e sinais neurológicos como convulsões, paralisia dos membros pélvicos, ataxia, nistagmo, tremores e hipermetria (VICENTE et al., 2010; GREENE \& APPEL, 2011).

ALMEIDA et al., (2009) relatam que após a infecção o vírus se multiplica nos macrófagos do trato respiratório e das tonsilas, e que o envolvimento da medula óssea representa uma rota de infecção para as outras células circulantes, como os leucócitos e os eritrócitos. Os principais achados hematológicos observados em cães com cinomose são a anemia, leucopenia e linfopenia (SILVA et al., 2005; AMUDE et al., 2007). No final da primeira semana após a infecção, os animais podem apresentar discreta neutropenia (ALMEIDA et al., 2009). A neutrofilia geralmente indica a presença de infecção bacteriana secundária (ALMEIDA et al., 2009).

Por ser uma doença multisistêmica, o diagnóstico clínico da cinomose ainda é um desafio para os médicos veterinários. O conhecimento dos parâmetros laboratoriais da doença pode orientar no diagnóstico e prognóstico. A maioria dos diagnósticos são baseados em: anamnese, sintomatologia e achados hematológicos consistentes (NELSON \& COUTO 2010).

Vários exames laboratoriais estão disponíveis para auxiliar no diagnóstico, como hemograma com pesquisa de inclusões virais, avaliação do líquor, sorologia 
por ELISA e diagnóstico molecular como a reação em cadeia de polimerase (PCR) (MONTEIRO et al., 2008). BARBOSA et al., (2011) afirmam que a visualização da inclusão viral do corpúsculo de Sinegaglia Lentz em eritrócitos ou leucócitos confere o diagnóstico definitivo da doença por representarem o efeito citopático do vírus sobre estas células. Estas inclusões caracterizam-se como corpúsculos redondos ou ovalados, com coloração eosinofílica quando presente no citoplasma de linfócitos e monócitos, eosinofílico à basofílico, em neutrófilos e nas hemácias apresentam formas arredondadas ou irregulares e de coloração azul clara, rósea ou vermelhoacastanhada (WALKER, 2009). SILVA et al., (2005) relatam que essas inclusões são encontradas em aproximadamente $21 \%$ dos animais infectados. Sendo que a presença das inclusões é frequente nos estágios iniciais da doença (WALKER, 2009).

O objetivo deste trabalho foi caracterizar as alterações hematológicas de cães com quadro clínico de cinomose, atendidos na Universidade Federal do Piauí, Campus Prof ${ }^{a}$ Cinobelina Elvas, no município de Bom Jesus/PI.

\section{MATERIAL E MÉTODOS}

Participaram deste estudo, 18 cães, sendo sete machos e 11 fêmeas, de diferentes raças e idades. Utilizaram-se apenas animais atendidos no setor de clínicas de pequenos animais na Universidade Federal do Piauí (UFPI) no Campus Profa Cinobelina Elvas (CPCE), no município de Bom Jesus - PI, com quadro clínico de cinomose e para os quais o hemograma foi solicitado para auxílio diagnóstico. $O$ estudo foi conduzido no município de Bom Jesus/PI, situado a 0904'28" de latitude sul e 4421'31" de longitude oeste, a 277 metros de altitude.

Foram coletados de 3 a $5 \mathrm{~mL}$ de sangue venoso por venopunção jugular e/ou cefálica, em tubos a vácuo contendo anticoagulante EDTA-K3 (ácido etilenodiaminotetracético) e imediatamente processados. A presença de anemia foi avaliada pelo hematócrito, por método de microhematócrito (Centrífuga de microhematócrito Spin 1000 - AAKER LTDA, São Paulo, Brasil). Para a avaliação dos leucócitos foi realizada contagem absoluta de leucócitos totais em câmera hemocitométrica, e o exame diferencial de leucócitos em 100 leucócitos em esfregaços sanguíneos corados com corante do tipo Romanowsky (Panótico Rápido - LABORCLIN LTDA, Pinhais/PR, Brasil). A estimativa do número de plaquetas, a análise morfológica das células e pesquisas de inclusões virais, em microscópio óptico de luz branca também foram realizadas no esfregaço sanguíneo. Todas as análises foram realizadas segundo as técnicas de Hendrix (2003), no laboratório de Patologia Clínica Veterinária da UFPI/CPCE.

\section{RESULTADOS E DISCUSSÃO}

Dos 18 animais estudados, em quatro $(22,2 \%)$ deles foi observada inclusão de Lentz, representando o efeito citopático do vírus no interior das células de animais com cinomose. Provavelmente estes animais estavam na fase virêmica, visto que nessa fase as inclusões ocorrem com maior frequência (WALKER, 2009; NOLETO et al., 2011). Resultado este semelhante ao descrito por MONTEIRO et al. (2008) onde encontraram essas mesmas inclusões em 17,6\% dos animais infectados. MONTEIRO et al. (2010) afirmam que a observação dos corpúsculos de Lentz nos leucócitos e ou hemácias confirma o diagnóstico definitivo para cinomose uma vez que as inclusões de Lentz são consideradas patognomônicas para esta doença. 
Nos animais que apresentaram inclusões em leucócitos elas foram observadas em pequena quantidade, sendo mais evidentes nos linfócitos e discretamente coradas nos neutrófilos (Figura 1). Grande quantidade de inclusões eosinofílicas de formato arredondado e/ou irregulares foram observadas nos animais com inclusões nas hemácias (Figura 2). Concordando com WALKER (2009), que afirmou que nos leucócitos os corpúsculos de Lentz apresentam-se em pequena quantidade, sendo visualizadas em maior quantidade quando presente nas hemácias. NOLETO et al., (2011) descrevem que o achado do corpúsculo de Lentz nos leucócitos é um grande indicativo que a doença está na fase de viremia ou no estado de latência e que a ausência destas inclusões nas células sanguíneas não descarta a possibilidade da doença.

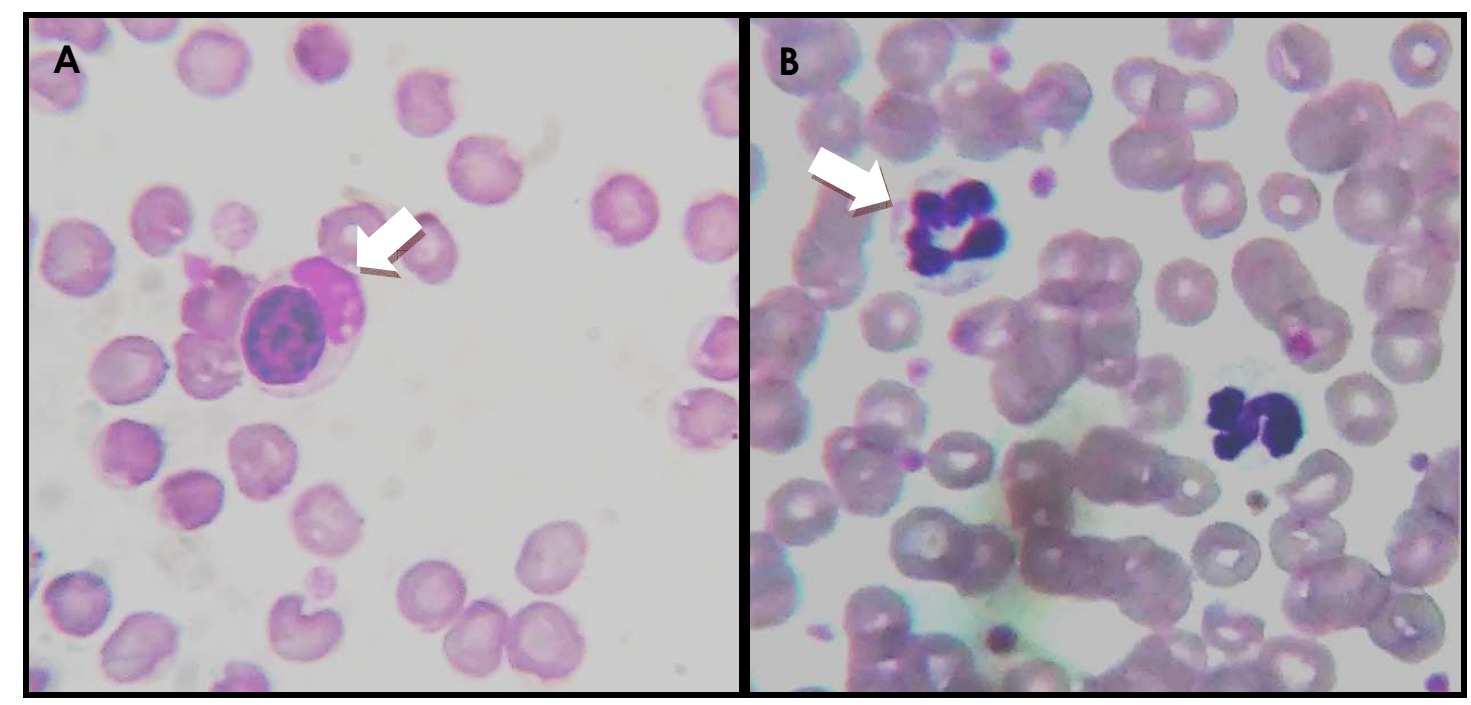

FIGURA 1. Fotomicrografia de inclusões (setas) de corpúsculos de Lentz no exame do esfregaço sanguíneo, de um cão com inclusões apenas em leucócitos, no aumento de 1000x. A) Linfócito com corpúsculo evidente e intensamente eosinofílico; B) Neutrófilo com pequeno corpúsculo, discretamente eosinofílico. Fonte: Arquivo Pessoal, 2015.
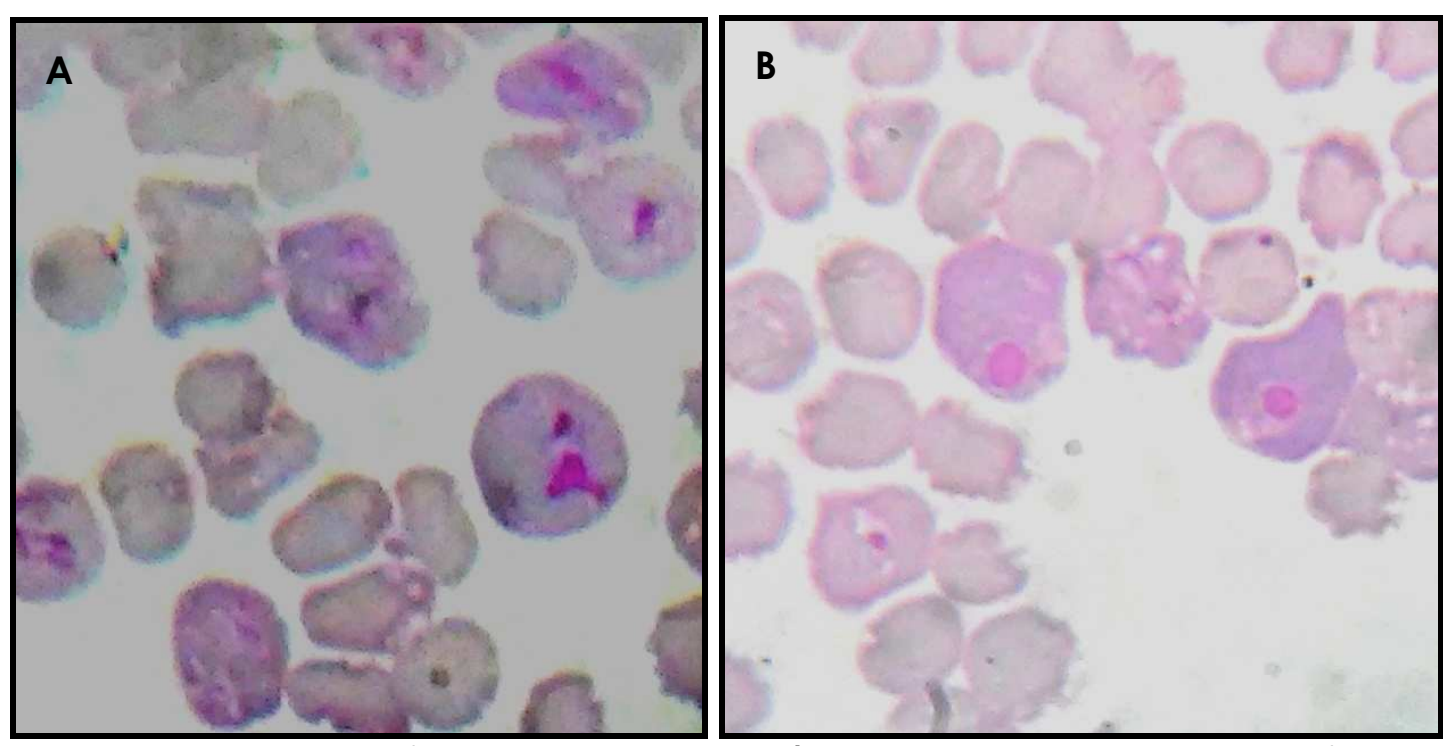

FIGURA 2. Fotomicrografia de inclusões de corpúsculos de Lentz no exame do esfregaço sanguíneo, de um cão com múltiplas inclusões eosinofílicas em eritrócitos, no 
aumento de 1000x. A) Eritrócitos maduros e policromatofílicos com inclusões de formato irregular. B) Eritrócitos policromatofílicos com inclusões arredondadas. Fonte: Arquivo Pessoal, 2015.

A cinomose canina ocorre principalmente em cães com três a seis meses de idade, devido ao desaparecimento da imunidade passiva transmitida pela mãe aos filhotes (BARBOSA et al., 2011; DIAS et al., 2012). Concordando com a literatura observou-se nesse estudo que houve uma maior ocorrência de sintomatologia em animais jovens de zero a um ano e meio de idade (67\%).

Em relação as raças, foi observada maior frequência de animais sem padrão de raça definida (SPRD), representando $72,2 \%$ (13), a frequência foi superior a observada por VICENTE et al., (2010) que encontraram 41\% (12) e GALANTE (2009) com 40\% (12) de animais SPRD. Essa maior frequência pode ter relação com a população local de cães que é constituída em sua maioria por SPRD e falta de esclarecimento e/ou condições financeiras dos proprietários para realizarem esquema de vacinação adequado.

Observou-se um discreto predomínio de fêmeas, com 11 casos $(61,1 \%)$ e sete casos em machos (38,9\%). Semelhante a GALANTE (2009), que observou 17 casos em fêmeas $(56,67 \%)$ e 13 casos em machos (43,33\%). Outros autores não acharam diferença significativa entre machos e fêmeas (FREITAS-FILHO et al., 2014). Mesmo havendo variação em relação à raça e ao sexo dos animais não houve diferença na apresentação da doença, corroborando com GALANTE (2009) e VICENTE et al., (2010).

Com relação à frequência das alterações hematológicas, a maioria dos animais apresentaram anemia, linfócitos reativos associados ou não a linfopenia, monocitose e trombocitopenia, dentre outras (Figura 3).

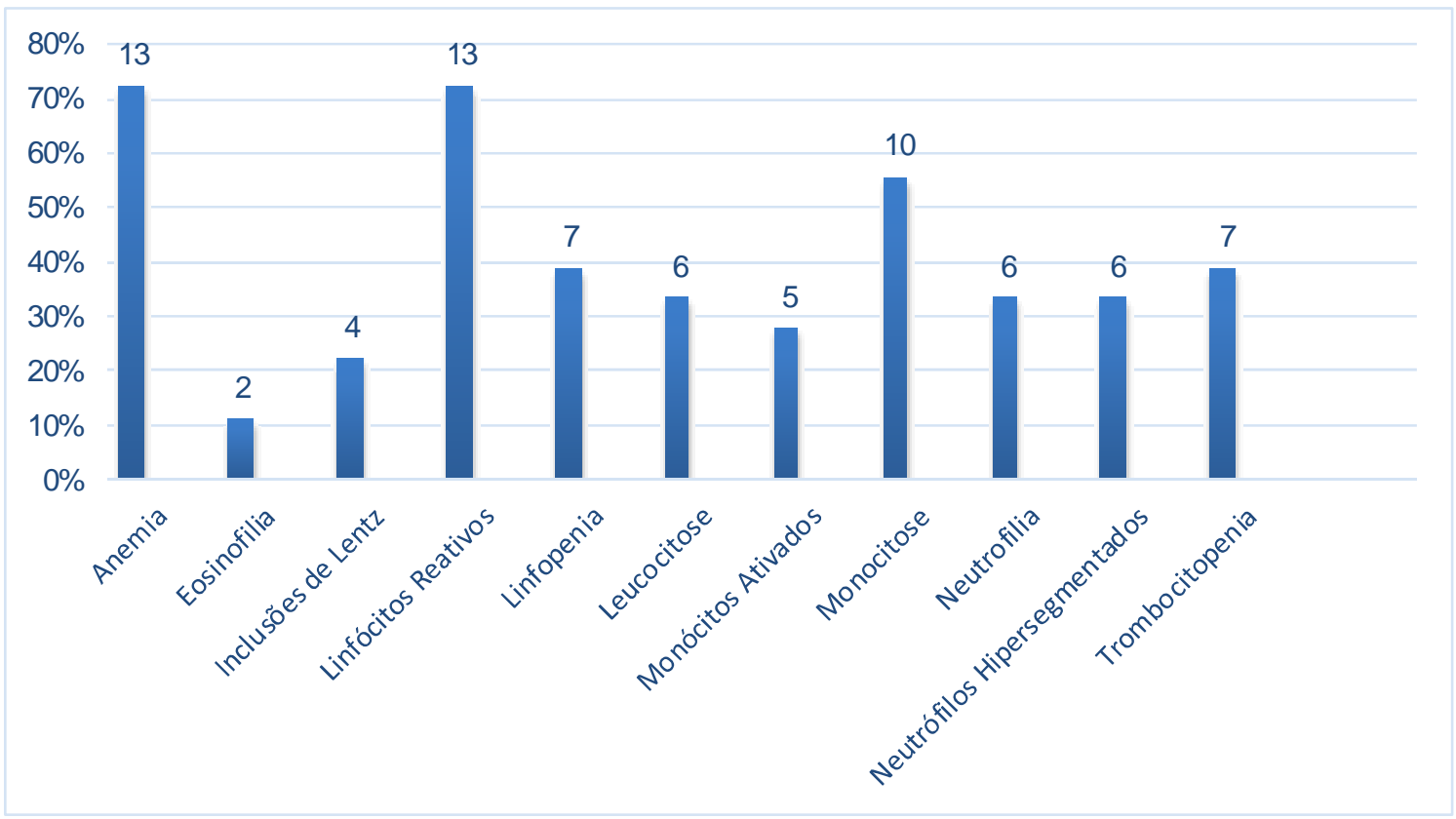

FIGURA 3. Porcentagem e número de animais que apresentaram alterações hematológicas com frequência superior a $20 \%$, em 18 cães com quadro clínico de cinomose em Bom Jesus, Piauí. 
De todos os animais avaliados, observou-se que $72,2 \%$ dos animais estavam anêmicos, com hematócrito variando de 13 a $35 \%$ (média = 26,8\%) o que corrobora com ALMEIDA et al., (2009); FREITAS-FILHO et al., (2014); FUNG et al., (2014) que relatam uma grande frequência de animais anêmicos em animais com cinomose. A anemia pode ser atribuída a destruição das células pela presença do vírus nos eritrócitos, ou pela deposição de imunocomplexos na membrana do mesmo (HEADLEY et al., 2012). Nos animais deste estudo foi observado que a maioria das anemias eram arregenerativas, compatíveis com causas de diminuição da produção e ou doenças em fase aguda, nas quais ainda não se observa resposta (WALKER, 2009).

Em quatro animais foram diagnosticadas doenças concomitantes, confirmadas pelo hemograma, sendo dois casos de erliquiose, dos quais um apresentava também leishmaniose; um caso de babesiose e um caso de anaplasmose. Essas doenças concomitantes podem ter contribuído para a anemia. MIRANDA et al., (2011) em relato de caso confirmaram erliquiose e babesiose concomitantemente com o vírus da cinomose canina. LEAL et al., (2011) por sua vez relataram uma infecção concomitante de cinomose com Cystoisospora ohioensis. E em ambos os relatos os animais apresentavam-se anêmicos.

Alguns autores confirmam que os principais achados hematológicos observados em cães com cinomose são: anemia, leucopenia por linfopenia (SILVA et al., 2005; AMUDE et al., 2007) e trombocitopenia, após a primeira semana de infecção podem apresentar uma discreta neutropenia, e estando a infecção associada com complicações bacterianas secundárias pode-se observar neutrofilia (ALMEIDA et al., 2009).

A principal alteração do leucograma foi a presença de linfócitos reativos (72,2\%), observados na avaliação morfológica. MANGIA (2011) observou que na cinomose as alterações comumente encontradas no hemograma são os linfócitos reativos, as inclusões de Lentz e os monócitos ativados. As formas reativas são provavelmente os linfócitos $T$ ou $B$ estimulados imunologicamente e envolvidos na síntese de mediadores inflamatórios e também imunoglobulinas, nos linfócitos B. Apresentam-se maiores e com citoplasma intensamente basofílico e a presença no sangue periférico indica estimulação antigênica ativa, porém inespecífica (WALKER, 2009).

A linfopenia é considerada uma característica marcante da infecção do Vírus da Cinomose Canina (VCC), mas pode estar ausente em alguns casos por não ser um achado específico. No presente estudo a linfopenia ocorreu, mas não foi predominante $(38,8 \%)$. GALANTE (2009) e BARBOSA et al., (2011) observaram linfopenia em $56,7 \%$ e $76 \%$ dos casos respectivamente. MANGIA (2011) observou uma linfopenia persistente em tratamentos de animais com cinomose. Também pode ser justificada pela atrofia e necrose do tecido linfoide, causada pelo vírus. FREITAS-FILHO et al., (2014) associam a ocorrência da linfopenia inicial com a elevação da temperatura corporal com posterior leucocitose neutrofílica.

No presente estudo, a monocitose (55,5\%) acompanhada de monócitos ativados $(27,7 \%)$, leucocitose $(33,3 \%)$, e neutrofilia (33,3\%) acompanhada por neutrófilos hipersegmentados foram alterações relevantes. Particularmente nos cães a monocitose e a neutrofilia podem ocorrer tanto em doenças inflamatórias agudas como crônicas, porém os animais que apresentaram neutrófilos hipersegmentados provavelmente estavam na fase crônica ou sob efeito de corticosteróides endógeno 
e/ou exógeno (WALKER, 2009). A capacidade dos cães de responder com neutrofilia mesmo na fase aguda deve-se a grande quantidade de células de reserva na medula óssea (WEISER, 2015).

As principais frequências de alterações na série branca, entre os animais positivos do estudo de GALANTE (2009) foram: leucocitose (40\%), neutrofilia $(56,7 \%)$, linfopenia $(56,7 \%)$ e monocitose $(10 \%)$. Ao contrário de BARBOSA et al., (2011) que observaram apenas a presença de linfopenia significantemente presente.

Pela estimativa do número de plaquetas no esfregaço sanguíneo foi observada trombocitopenia em $38,8 \%$ dos animais estudados. O que corrobora com GALANTE (2009), VICENTE et al., (2011) e SANTOS et al., (2012) que observaram $36,1 \%, 36,7 \%$ e $50,33 \%$ respectivamente. A linfocitopenia e a trombocitopenia são alterações hematológicas consistentes para o diagnóstico da cinomose (NELSON \& COUTO, 2010).

SILVA et al., (2005) sugeriram que a trombocitopenia ocorre por um processo imunomediado, com a retirada das plaquetas da circulação através de macrófagos pelo sistema retículo endotelial e segundo RIMA \& DUPREX (2006) esta trombocitopenia é um achado transitório que desaparece com três a quatro semanas após a infecção.

TABELA 1. Valores individuais, média e desvio padrão (DP) do leucograma de 18 cães com quadro clínico de cinomose em Bom Jesus, Piauí

\begin{tabular}{cccccccc}
\hline Animais & $\begin{array}{c}\mathbf{L T} \\
\left(\mathbf{x} \mathbf{1 0}^{3} \boldsymbol{\mu L}\right)\end{array}$ & $\begin{array}{c}\text { Bastonetes } \\
(\boldsymbol{\mu L})\end{array}$ & $\begin{array}{c}\text { Neutrófilos } \\
\text { Segmentados } \\
(\boldsymbol{\mu} \mathrm{L})\end{array}$ & $\begin{array}{c}\text { Linfócitos } \\
(\boldsymbol{\mu} \mathrm{L})\end{array}$ & $\begin{array}{c}\text { Eosinófilos } \\
(\boldsymbol{\mu} \mathrm{L})\end{array}$ & $\begin{array}{c}\text { Basófilos } \\
(\boldsymbol{\mu} \mathrm{L})\end{array}$ & $\begin{array}{c}\text { Monócitos } \\
(\boldsymbol{\mu} \mathrm{L})\end{array}$ \\
\hline $\mathbf{0 1}$ & 10,5 & 210 & 7.665 & 630 & 0,0 & 0,0 & 1.995 \\
$\mathbf{0 2}$ & 13,0 & 0,0 & 9.660 & 2.470 & 130 & 0,0 & 1.040 \\
$\mathbf{0 3}$ & 11,2 & 0,0 & 7.168 & 560 & 560 & 0,0 & 1.344 \\
$\mathbf{0 4}$ & 5,3 & 212 & 4.770 & 106 & 0,0 & 0,0 & 212 \\
$\mathbf{0 5}$ & 29,9 & 0,0 & 23.920 & 598 & 299 & 299 & 4.784 \\
$\mathbf{0 6}$ & 15,9 & 0,0 & 8.427 & 5.565 & 318 & 0,0 & 1.590 \\
$\mathbf{0 7}$ & 43,0 & 0,0 & 34.444 & 5.232 & 436 & 0,0 & 3.488 \\
$\mathbf{0 8}$ & 30,15 & 0,0 & 25.024 & 1.206 & 904 & 0,0 & 3.015 \\
$\mathbf{0 9}$ & 15,1 & 151 & 9.211 & 2.416 & 755 & 0,0 & 2.567 \\
$\mathbf{1 0}$ & 25,55 & 0,0 & 17.325 & 450 & 2.475 & 0,0 & 2.250 \\
$\mathbf{1 1}$ & 17,15 & 0,0 & 10.290 & 4.459 & 171 & 0,0 & 2.229 \\
$\mathbf{1 2}$ & 8,8 & 0,0 & 5.368 & 1.056 & 176 & 0,0 & 2.200 \\
$\mathbf{1 3}$ & 11,15 & 0,0 & 8.585 & 557 & 1.450 & 112 & 446 \\
$\mathbf{1 4}$ & 9,8 & 0,0 & 6.370 & 2.254 & 294 & 0,0 & 882 \\
$\mathbf{1 5}$ & 13,7 & 0,0 & 8.083 & 3.562 & 822 & 137 & 1.096 \\
$\mathbf{1 6}$ & 16,6 & 0,0 & 9.512 & 812 & 696 & 0,0 & 580 \\
$\mathbf{1 7}$ & 4,6 & 0,0 & 2.530 & 1.840 & 0,0 & 0,0 & 230 \\
$\mathbf{1 8}$ & 18,0 & 0,0 & 13.680 & 1.260 & 720 & 0,0 & 2.340 \\
\hline Média & $\mathbf{1 6 . 6 3 3}$ & & $\mathbf{1 1 . 7 8 0}$ & $\mathbf{1 . 9 4 6}$ & $\mathbf{5 6 7}$ & & $\mathbf{1 . 7 9 4}$
\end{tabular}




\begin{tabular}{ccccccc} 
DP & $\mathbf{9 . 8 1 8}$ & & $\mathbf{8 . 2 8 8}$ & $\mathbf{1 . 7 0 7}$ & $\mathbf{6 1 2}$ & \\
\hline VR & $6.000 \mathrm{a}$ & $0 \mathrm{a} 500$ & $3.000 \mathrm{a}$ & $1.000 \mathrm{a}$ & 1.217 \\
\hline
\end{tabular}

LT = Leucócitos Totais; VR = Valores de Referência (WALKER, 2009).

A leucopenia não foi um achado frequente neste estudo com apenas 1 caso (5,56\%), já VICENTE et al., (2010) e BARBOSA et al., (2011) encontraram 10\% e $16 \%$ respectivamente. Ressaltando a importância da avaliação da leucometria diferencial, visto que apesar dos leucócitos totais estarem normais os animais apresentavam alterações variáveis em vários tipos celulares (Tabela 1). Por se tratar de infecção natural os animais apresentavam-se em diferentes fases da doença e sabe-se que a resposta hematológica varia também de um indivíduo para outro e com a fase da infecção viral (SILVA et al., 2005).

Em menor proporção ocorreram eosinofilia e basofilia. Segundo WEISER (2015), a eosinofilia é interpretada como uma resposta inespecífica e deve-se sempre considerar a possibilidade de parasitismo, hipersensibilidade ou inflamação de superfícies ricas em mastócitos, como pele, trato respiratório e gastrointestinal. O VCC provoca distúrbios gástricos e do trato respiratório (BEINEKE et al., 2009), que também podem ter induzido a resposta eosinofílica observada.

\section{CONCLUSÃO}

Conclui-se que a anemia e a ativação dos linfócitos são os achados mais relevantes na cinomose canina, podendo estar ou não associados à linfopenia. A avaliação da morfologia leucocitária e pesquisa dos corpúsculos de Lentz deve ser realizada em todos os animais com suspeita de cinomose canina, sendo importante ferramenta para o diagnóstico e estadiamento da doença.

\section{REFERENCIAS}

ALMEIDA, R. K.; VASCONCELOS, A. C.; CARNEIRO, R. A.; PAES, P. R. O.; MORO, L. Alterações citológicas do sangue periférico e da medula óssea de cães com cinomose. Arquivos Brasileiro de Medicina Veterinária e Zootecnia, v. 61, n. 6, p. 1255-1260, 2009.

AMUdE, A. M.; ALFIERI, A. A.; ALFIERI, A. F. Clinic pathological findings of distemper encephalomyelitis in dogs presented without usual signs of the disease. Research in Veterinary Science, v. 82, p. 416-422, 2007.

BARBOSA, T. S.; VIEIRA, R. F. C.; VIOL, M. A.; SOEIRO, C. S.; BOMFIM, S. R. M.; CIARLINI, P. C. Avaliação laboratorial da cinomose canina - estudo retrospectivo de 25 casos no município de Araçatuba, SP. Revista de Ciências Agroveterinárias, v. 10, n. 2, p. 113-118, 2011.

BEINEKE, A.; PUFF, C.; SEEHUSEN, F.; BAUMGÄRTNER, W. Pathogenesis and immunopathology of systemic and nervouscanine distemper. Veterinary Immunology and Immunopathology, n. 127, p. 1-18, 2009.

DIAS, M. B. M. C.; LIMA, E. R.; FUKAHORI, F. L. P.; SILVA, V. C. L.; RÊGO, M. S. A. Cinomose canina: Revisão de Literatura. Medicina Veterinária, v. 6, n. 4, p. 3240, 2012. 
FREITAS-FILHO, E. G.; FERREIRA, M. R. A.; DIAS, M.; MOREIRA, C. N. Prevalência, fatores de risco e associações laboratoriais para cinomose canina em Jataí-GO. Enciclopédia Biosfera, v. 10, n. 18, p. 2356-2365, 2014.

FUNG, H. L.; CALZADA, J.; SALDANA, A.; SANTAMARIA, A. M.; PINEDA, V.; GONZALEZ, K.; CHAVES, L. F.; GARNER, B.; GOTTDENKER, N. Domestic dog health worsens with socio-economic deprivation of their home communities. Acta Tropica, v. 135, p. 67-74, 2014.

GALANTE, A. C. Imunocromatografia, observações clínica, hematológica e bioquímica sérica de cães (Canis familiaris) com suspeita de cinomose. Dissertação (Mestrado em Ciência Animal - Sanidade Animal) Universidade Estadual do Norte Fluminense Darcy Ribeiro, Campo dos Goytacazes, 2009.

GREENE, C. E.; APPEL, M. J. Canine Distemper. In: GREENE, C. E. Infectious Diseases of the Dog and Cat. 4 ed. St Louis: Elsevier, p.25-41. 2011.

HEADLEY, S. A.; AMUDE, A. M.; ALFIERI, A. F.; ALFIERI, A. A.; BRACARENSE, A. P. F. R. L. Epidemiological features and the neuropathological manifestations of canine distemper virus-induced infections in Brazil: a review. Semina: Ciências Agrárias, Londrina, v.33, n.5, p.1945-1978, 2012.

HENDRIX, C. M. Procedimentos laboratoriais para técnicos veterinários. São Paulo: Roca, 2003. 556p.

KING, A. M. Q.; ADAMS, M. J.; CARSTENS, E. B.; LEFKOWITZ, E. J. II section the negative sense single stranded RNA viruses. In: KING, A. M. Q.; ADAMS, M. J.; CARSTENS, E. B.; LEFKOWITZ, E. J. Virus Taxonomy: Ninth Report of the International Committee on Taxonomy of Viruses. San Diego: Academic Press, 2011. $1338 \mathrm{p}$.

LEAL, P. D. S.; PONTES, P. R.; FLAUSINO, W.; LOPES, C. W. G. Diagnóstico de infecções concomitantes por Cystoisospora ohioensis e o vírus da cinomose Relato de Dois Casos. Revista Brasileira de Medicina Veterinária, v. 33, n. 3, p. 184-188, 2011.

MANGIA, S. H. Avaliação do tratamento experimental de cães naturalmente infectados com vírus da cinomose na fase neurológica com ribavirina, prednisona e DMSO através da RT-PCR. Tese (Doutorado em Medicina Veterinária) - Universidade Estadual Paulista - Faculdade de Medicina e Veterinária e Zootecnia, SP, 2011.

MIRANDA, F. J. B.; AlBeRnAZ, A. P.; VIESTEL, M. A. D.; MElO-JR, O. A.; MACHADO, J. A.; ALVES, R. B. M.; CARVALHO, C. B. Infecção simultânea por Ehrlichia canis, Babesia canis e vírus da cinomose canina - Relato de Caso. Jornal Brasileiro de Ciência Animal, v. 3, n. 6, p. 238-246, 2011. 
MONTEIRO, M. V. B.; SANTOS, M. P.; FIGUEIREDO, M. J. F. M.; MONTEIRO, F. O. B. Avaliação clínica e hematológica de cães com cinomose em Belém, Pará. Ciência Animal, v. 18, n. 1, p. 41-44, 2008.

MONTEIRO, M. V. B.; SANTOS, M. P.; COSTA, C. T. C.; WHITEMAN, C. W.; MONTEIRO, F. O. B. Cinomose canina nos animais domésticos e silvestres. Revista de Ciências Agrárias Amazonian Journal, v.53, n.2, p.216-223, 2010.

NELSON, R. W.; COUTO, C. G. Medicina interna de pequenos animais. 4.ed. Rio de Janeiro: Elservier, 2010. 1674p.

NOLETO, P. G.; MENDONÇA, C. S.; FERNANDES, C. C.; MANTOVANI, M. M.; TSURUTA, S. A.; SOLA, M. C.; MUNDIM, A. V. Corpúsculos de Lentz em um cão com 10 dias de idade. Bioscience Journal, v. 27, n. 1, 2011.

OLIVEIRA, A. C.; ANTONIO, N. S.; ZAPPA, V. Cinomose canina - Relato de Caso. Revista Científica Eletrônica de Medicina Veterinária, Ano VII, n. 12, 2009.

RIMA, B. K.; DUPREX, W. P. Morbilliviruses and human disease. The Journal of Pathology, v. 208, n. 2, p. 199-214, 2006.

SANTOS, J. P.; BORGES, C. E. F.; LOCCE, C. C.; JUNIOR, A. F.; BITTAR, E. R.; AYRES, D. R.; BITTAR, J. F. F. Estudo Retrospectivo de Cães Positivos para Cinomose, em Ensaio Imunocromatográfico, atendidos no Hospital Veterinário de Uberaba-MG. Veterinária Notícias, v. 18, n. 2, p. 31-36, 2012.

SILVA, I. N. G.; GUEDES, M. I. F.; ROCHA, M. F. G.; MEDEIROS, C. M. O.; MOREIRA, O. C.; TEIXEIRA, M. F. S. Perfil hematológico e avaliação eletroforética das proteínas séricas de cães com cinomose. Arquivo Brasileiro de Medicina Veterinária e Zootecnia, v. 57, n.1, p.136-139, 2005.

VICENTE, A. F.; ABREU, A. P. M.; PASSOS, A. A. M. S. Perfil hematológico em cães infectados naturalmente por cinomose com presença de corpúsculo de Sinegaglia Lentz, em Vassouras - RJ. Revista de Saúde, v. 1, n. 1, p. 49-54, 2010.

WALKER, D. Esfregaços de sangue periférico. In: COWELL, R.L.; TYLER, R.D.; MEINKOTH, J.H.; DeNICOLA, D.B. Diagnóstico citológico e hematológico de cães e gatos. 3. ed. São Paulo: MedVet. p.390 - 422. 2009.

WEISER, G. Interpretação da resposta leucocitária na doença. In: TRALL, M. A.; WEISER, G.; ALLISON, R.W.; CAMPBELL, T.W. Hematologia e Bioquímica Clínica Veterinária. 2. ed. São Paulo: Roca. p.108 - 119.2015. 